\title{
Observatorio
}

\section{El sector editorial español}

\author{
Por Pedro De-Andrés-Romero
}

Resumen: Se plantea una visión del estado de la cuestión en el sector de la edición, teniendo en cuenta las diferentes materias. Se aportan datos de los mercados interior y exterior del libro, y se analiza la situación de la industria editorial española en relación con el mundo digital, que ha mantenido una posición de atención continua a la evolución de las tecnologías de la información.

Palabras clave: Edición, Industria editorial, Mercado exterior del libro, Mercado interior del libro, Sector editorial, Tecnologías de la información.

\section{Title: The Spanish publishing sector}

Abstract: An overview of the current status of the publishing sector, taking into account each subject area. Data is furnished on the domestic and foreign book markets and an analysis is made of the situation of the Spanish publishing industry with respect to the digital world and the close attention being paid to the development of information technologies.

Keywords: Publication, Publishing industry, Foreign book market, Domestic book market, Information technologies.

De-Andrés-Romero, Pedro. "El sector editorial español”. El profesional de la información, 2010, enero-febrero, v.19, n. 1 , pp. 5-11.

DOI: $10.3145 /$ epi.2010.ene.01

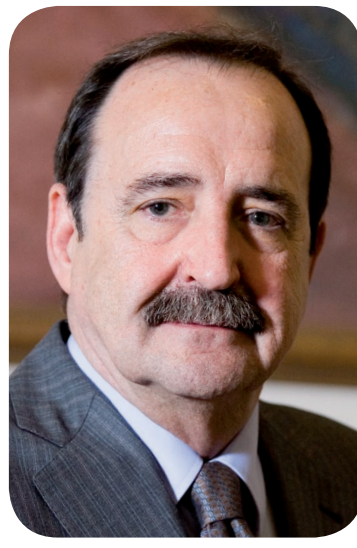

Pedro De-Andrés-Romero es licenciado en ciencias biológicas por la Univ. Complutense de Madrid. Tras una etapa dedicada a la docencia, entra en contacto con el sector editorial como articulista y asesor en temas de naturaleza y ecología en diversas revistas y para Alianza Editorial. Posteriormente, y bajo la dirección de Félix Rodríguez de la Fuente, forma parte del equipo de redacción de la Enciclopedia Fauna para Salvat Editores. En 1974 se incorpora a Ediciones Anaya como editor de Ciencias Naturales, para, a continuación, dirigir el Departamento de Ciencias de dicha editorial. En 1977 se traslada a México como director de publicaciones y subgerente general del antiguo grupo cultural, hoy Grupo Patria. En 1987 regresa a España para desempeñar el cargo de director editorial para Iberoamérica de Grupo Anaya, y pasar después a ejercer de director adjunto a la presidencia y director de relaciones institucionales. Ha participado activamente en las instituciones del sector editorial español, ostentando distintos cargos, siendo el último el de presidente de la Federación de Gremios de Editores de España.
EL SECTOR EDITORIAL ESPAÑOL está compuesto por una amplia gama de agentes editores. Aquéllos que tienen como principal actividad económica la edición, casi todos ellos afiliados a los gremios o asociaciones que se integran en la Federación de Gremios de Editores de España (FGEE) -cerca de 900-, representan aproximadamente el $95 \%$ del volumen del sector $y$, a lo largo de 2008 , publicaron más de $\mathbf{2 4 0}$ millones de libros de un total de $\mathbf{7 2 . 9 8 2}$ títulos, con una tirada media de $\mathbf{5 . 0 3 5}$ ejemplares.

La industria editorial española mueve anualmente más de 3.000 millones de euros (un $0,7 \%$ del PIB) y da empleo, directo e indirecto, a más de 30.000 personas.

El informe de comercio interior del libro en España, que se publica cada año por la $F G E E$, así como el de comercio exterior, publicado por la Federación de Cámaras del Libro (Fedecali), dan puntual cuenta de las magnitudes del sector editorial, así como de su evolución en el tiempo.

\section{Mercado interior del libro}

Según el último estudio publicado, correspondiente a 2008, la cifra global de negocio del sector en el mercado interior (a PVP, IVA incluido) ascendió a 3.185,5 millones de euros, lo que representó un incremento del $2 \%$ sobre el año anterior (gráfico 1).

Este crecimiento fue casi la mitad del experimentado en 2007, lo que se atribuye a los efectos de la crisis económica mundial aunque su impacto fue moderado, pues cuando se presentó ya habían transcurrido tres trimestres del año y la campaña escolar había finalizado.

"La industria editorial española mueve anualmente más de $\mathbf{3 . 0 0 0}$ millones de euros

(un $0,7 \%$ del PIB) y da empleo, directo e indirecto, a más de $\mathbf{3 0 . 0 0 0}$ personas" 


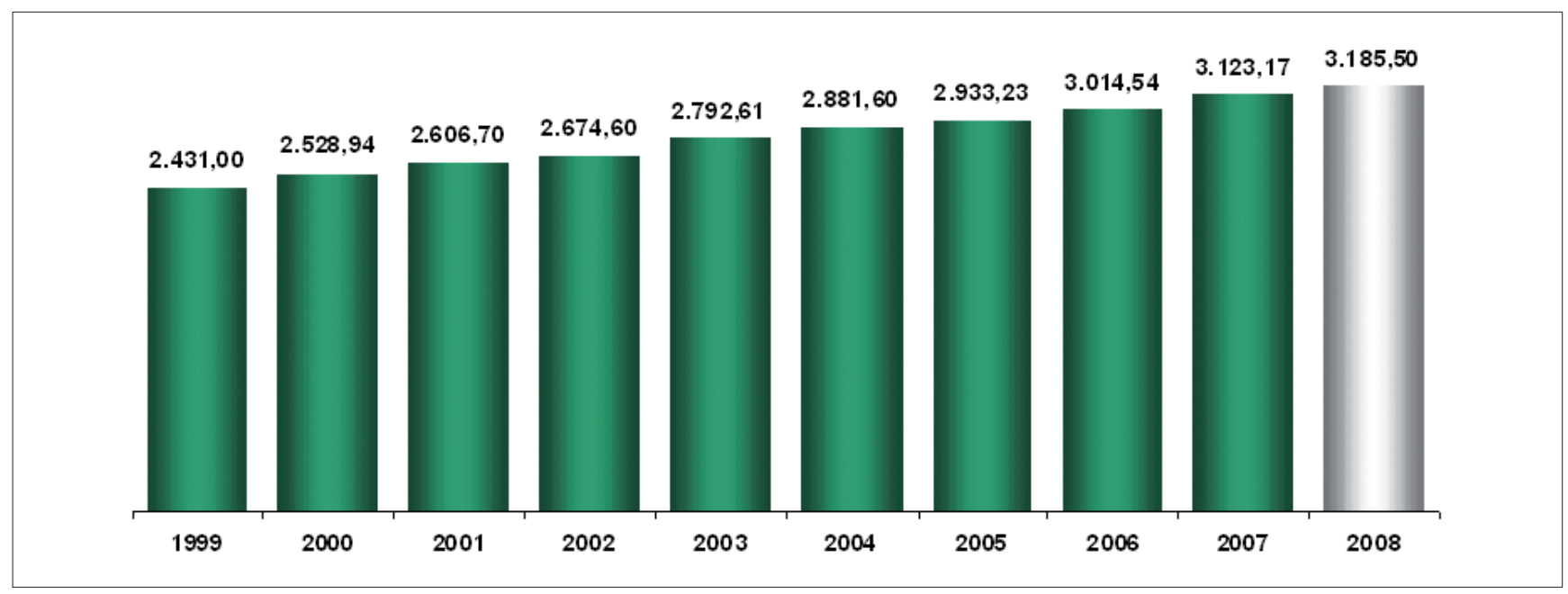

Gráfico 1. Facturación del comercio interior 1999-2008

Fuente: Comercio interior del libro en España 2008

En el gráfico 2 se muestra la evolución de las ventas en el mercado interior en los últimos diez años, comparando precios corrientes y constantes. Se pone de manifiesto el descenso efectivo del 1,2\% en moneda constante sobre las magnitudes de 1999.

Sobre el año 2009, en estos momentos sólo pueden hacerse aproximaciones, aún sin valor estadístico. A 30 de junio se vislumbraba una bajada en las ventas, frente al mismo período de 2008 , de cerca del $6 \%$ en términos generales. Cierto es que la aparición de títulos de autores de indiscutible éxito (Brown, Larsson, Myers, Zafón, etc.) puede elevar las ventas -por supuesto las de sus editoriales- y contribuir a una ligera mejoría al final del año.

La cifra global de facturación ofrece una imagen de la situación económica del sector en general. Del análisis de la facturación por materias en 2008 pueden extraerse algunas conclusiones que se muestran en la tabla 1 .
Es evidente la tendencia ascendente sostenida de la materia literatura, debida en exclusiva a la novela, y el más que notable aumento del texto no universitario debido, en su mayor parte, a la implantación de los nuevos currículos derivados de la aplicación de la LOE. La materia ciencias sociales y humanidades ha continuado creciendo en facturación de forma sostenida.

Por el contrario, el libro científico técnico y universitario ha seguido su trayectoria de descenso continuo, que cabe atribuir al negativo impacto que sobre esta materia tiene la reprografía ilegal, e incluso la piratería.

La comercialización del libro en el mercado interior se ha llevado a cabo mediante los canales que se muestran en la tabla 2 con su facturación correspondiente.

La mayor parte de la facturación -el 32\%- se realizó mediante el canal de librerías, situación que se mantiene en los últimos cinco años. Si a ésta se le añade la efec-

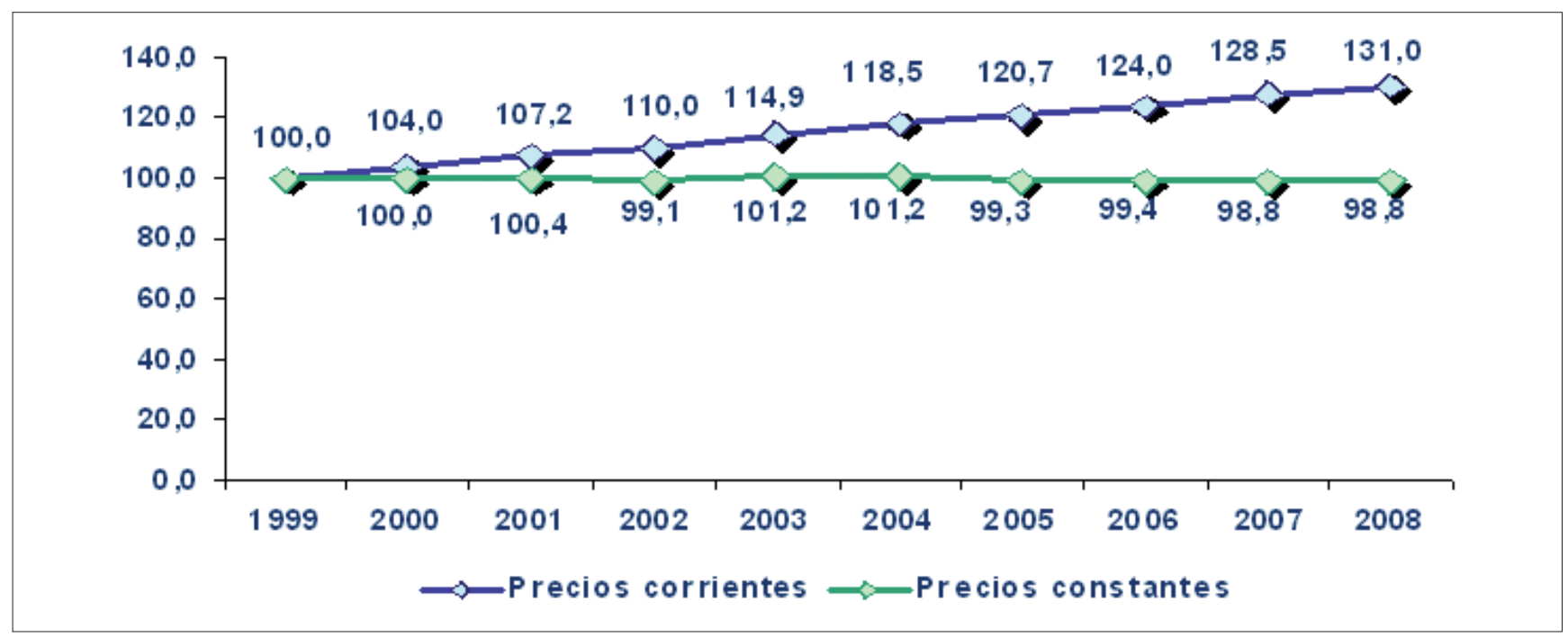

Gráfico 2. Evolución de las ventas en el mercado interior 1999-2008 Fuente: Comercio interior del libro en España 2008 


\begin{tabular}{|c|c|c|c|c|c|c|c|}
\hline \multirow{3}{*}{ Literatura } & 2004 & 2005 & 2006 & 2007 & \multicolumn{2}{|c|}{2008} & \multirow{3}{*}{$\begin{array}{c}\begin{array}{c}\text { Variación } \\
2008 / 2007\end{array} \\
4,2\end{array}$} \\
\hline & \multicolumn{4}{|c|}{ Millones de $€$} & \multirow{2}{*}{$\begin{array}{l}\text { Mills. } € \\
691,07 \\
\end{array}$} & \multirow{2}{*}{$\begin{array}{l}\% \\
21,7\end{array}$} & \\
\hline & 624,74 & 628,46 & 637,49 & 663,35 & & & \\
\hline Novela & - & - & 558,64 & 573,43 & 611,69 & 19,2 & 6,7 \\
\hline Poesía, teatro & - & - & 34,48 & 34,00 & 30,07 & 0,9 & $-11,6$ \\
\hline Otros literatura & - & - & 44,37 & 55,92 & 49,31 & 1,5 & $-11,8$ \\
\hline Infantil y juvenil & 274,73 & 281,74 & 323,53 & 330,32 & 326,99 & 10,3 & $-1,0$ \\
\hline Texto no universitario & 689,86 & 698,84 & 736,43 & 803,69 & 898,28 & 28,2 & 11,8 \\
\hline Educación infantil & 91,86 & 91,64 & 97,29 & 102,71 & 109,15 & 3,4 & 6,3 \\
\hline Educación primaria & 239,98 & 253,68 & 285,81 & 311,92 & 362,03 & 11,4 & 16,1 \\
\hline E.S.O. & 215,50 & 201,46 & 198,18 & 216,38 & 252,14 & 7,9 & 16,5 \\
\hline Bachillerato & 66,11 & 63,39 & 60,35 & 64,29 & 81,10 & 2,5 & 26,1 \\
\hline F.P. & 16,39 & 15,58 & 13,42 & 17,83 & 13,78 & 0,4 & $-22,7$ \\
\hline Libros y materiales complementarios & 60,02 & 73,09 & 81,39 & 90,56 & 80,09 & 2,5 & $-11,6$ \\
\hline Científico, técnico y universitario & 227,10 & 189,45 & 162,29 & 175,78 & 158,32 & 5,0 & $-9,9$ \\
\hline Total C. Sociales y Humanidades & 270,98 & 308,39 & 366,16 & 354,51 & 381,28 & 12,0 & 7,6 \\
\hline Ciencias Sociales y Humanidades & 270,98 & 308,39 & 366,16 & 205,41 & 170,35 & 5,3 & $-17,1$ \\
\hline Derecho y Ciencias Económicas & - & - & - & 118,23 & 174,64 & 5,5 & 47,7 \\
\hline Religión & - & - & - & 30,87 & 36,29 & 1,1 & 17,6 \\
\hline Libros prácticos & 177,49 & 179,57 & 192,11 & 184,74 & 168,89 & 5,3 & $-8,6$ \\
\hline Divulgación general & 203,72 & 211,84 & 248,64 & 281,36 & 260,22 & 8,2 & $-7,5$ \\
\hline Diccionarios y enciclopedias & 229,27 & 223,84 & 161,96 & 148,80 & 145,88 & 4,6 & $-2,0$ \\
\hline Cómics & 96,65 & 98,78 & 83,03 & 77,05 & 84,87 & 2,7 & 10,1 \\
\hline Otros & 87,06 & 112,30 & 102,90 & 103,57 & 69,70 & 2,2 & $-32,7$ \\
\hline TOTAL & $2.881,60$ & $2.933,23$ & $3.014,54$ & $3.123,17$ & $3.185,50$ & 100,0 & 2,0 \\
\hline
\end{tabular}

Tabla 1. Facturación por materias

Fuente: Comercio interior del libro en España 2008

tuada por las cadenas de librerías (Corte Inglés, FNAC, Casa del Libro, VIPS y similares) casi se alcanza la mitad de la facturación del mercado interior. Notable fue el crecimiento de las suscripciones, continuando una trayectoria ascendente, mientras que parece confirmarse la tendencia a la baja de las ventas a crédito.

\section{Mercado exterior del libro}

Las exportaciones del sector del libro español en 2008 totalizaron 545,98 millones de euros, lo que supuso un descenso del 1,61\% frente al ejercicio 2007. Sin embargo, con las cifras expresadas en dólares USA las ventas al exterior supusieron 802,59 millones, un $6,34 \%$ más que el año anterior.

Es ilustrativo comparar la exportación del sector del libro en euros, con la tasa de cambio euro/dólar USA a lo largo de los años, como se representa en el gráfico 3. En él se puede apreciar claramente la sensibilidad de la cifra de ventas de la exportación, en euros, al tipo de cambio del momento.

Del total de ventas de 2008, las realizadas por el sector editorial alcanzaron la cifra de 350,79 millones de euros, a pesar de anotar una caída del 3,7\%, mientras que las del sector gráfico ascendieron a $195,18 \mathrm{mi}-$ llones, un 2,5\% más que en 2007. Como es habitual, el saldo neto del comercio exterior del libro (exportaciones menos importaciones) resultó positivo, ascendiendo a 298 millones de euros.

"Las exportaciones del sector del libro español en 2008 totalizaron 546 millones de euros: un descenso del 1,61\% frente al ejercicio 2007" 


\begin{tabular}{|l|r|r|r|r|r|r|}
\hline & $\mathbf{2 0 0 4}$ & $\mathbf{2 0 0 5}$ & $\mathbf{2 0 0 6}$ & $\mathbf{2 0 0 7}$ & $\mathbf{2 0 0 8}$ & $\mathbf{2 0 0 8 / 2 0 0 7}$ \\
\hline Librerías & 998,79 & 960,53 & $1.003,06$ & 991,75 & $1.032,37$ & 4,1 \\
\hline Cadenas de librerías & 417,31 & 471,53 & 462,66 & 483,47 & 481,29 & $-0,5$ \\
\hline Hipermercados & 293,55 & 287,91 & 286,00 & 292,55 & 288,27 & $-1,5$ \\
\hline Quioscos & 148,24 & 156,47 & 170,60 & 272,08 & 242,76 & $-10,8$ \\
\hline Empresas e Instituciones & 238,62 & 250,88 & 278,43 & 304,37 & 331,63 & 9,0 \\
\hline Bibliotecas & 15,63 & 14,00 & 23,19 & 22,59 & 21,45 & $-5,1$ \\
\hline Venta a crédito & 282,14 & 281,10 & 253,72 & 258,92 & 215,82 & $-16,6$ \\
\hline Venta telefónica & 105,78 & 92,19 & 91,30 & 77,08 & 78,44 & 1,8 \\
\hline Correo & 100,36 & 116,05 & 100,04 & 88,90 & 71,43 & $-19,6$ \\
\hline Clubs & 112,65 & 113,17 & 115,27 & 116,66 & 102,19 & $-12,4$ \\
\hline Internet & 24,95 & 24,26 & 20,48 & 20,52 & 20,12 & $-2,0$ \\
\hline Suscripciones & 37,06 & 33,35 & 49,41 & 77,48 & 105,35 & 36,0 \\
\hline Otros canales & 106,52 & 131,80 & 160,36 & 116,80 & 194,38 & 66,4 \\
\hline $\begin{array}{l}\text { Total facturación } \\
\text { (millones de euros) }\end{array}$ & $\mathbf{2 . 8 8 1 , 6 0}$ & $\mathbf{2 . 9 3 3 , 2 3}$ & $\mathbf{3 . 0 1 4 , 5 4}$ & $\mathbf{3 . 1 2 3 , 1 7}$ & $\mathbf{3 . 1 8 5 , 5 0}$ & $\mathbf{2 , 0}$ \\
\hline
\end{tabular}

Tabla 2. Canales de comercialización

Fuente: Comercio interior del libro en España 2008

De nuevo hay que decir que no pueden hacerse sino aproximaciones sin valor estadístico para el año 2009, el cual, tras un comienzo muy débil, ha ido progresando a lo largo de los últimos meses, por lo que es posible suponer que puede acabar decorosamente.

\section{El mundo digital y la industria editorial española}

La industria editorial española ha mantenido una posición de atención continua a la evolución de las tec- nologías de la información y la comunicación (TIC), asumiendo con rapidez los diferentes avances tecnológicos, comenzando hace años por los procesos de autoedición (desktop publishing, DTP, como se llamó), pasando por la impresión digital sin intermediación de películas fotosensibles, directo a plancha (computer to plate, CTP) y llegando a la publicación de contenidos digitales sobre distintos soportes, sean materiales (DVD, CD) o electrónicos (la Red).

En 2008 un 24,7\% de las editoriales españolas pu-

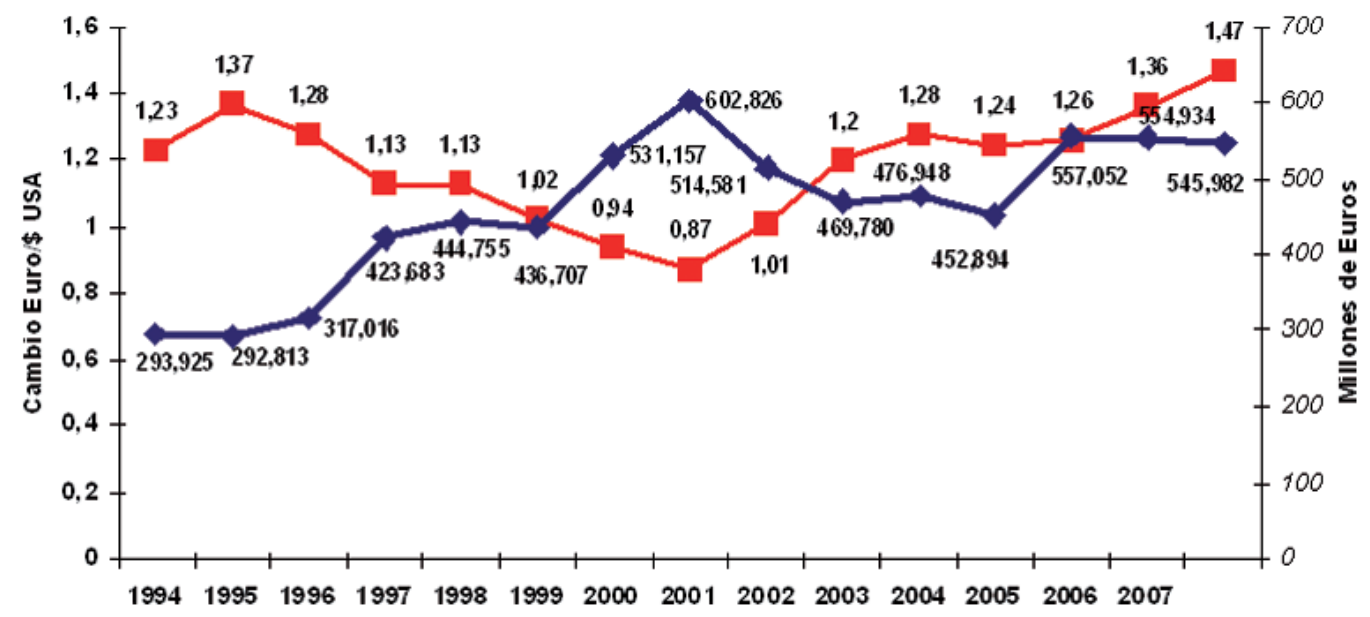

Gráfico 3. Evolución de las exportaciones totales y el cambio del \$ USA

Fuente: Comercio exterior del libro 2008 
blicaron en soportes distintos del papel, siendo la facturación correspondiente a estos "otros soportes" el $10,1 \%$ del total de la facturación del sector editorial en el mercado interior.

A nadie escapa que el libro electrónico (o digital, o $e$-book) está teniendo una presencia intensa en los medios de comunicación. Tal vez por ello, y por la expectación que se ha desatado, resulte conveniente realizar algunas precisiones al respecto.

El desencadenante (o desencadenantes) de esta oleada de expectativas han sido los dispositivos de lectura portátiles que, sobre la base de un cierto "aire de familia" con el libro de papel, aportan nuevas funciones (letra escalable, fuentes sustituibles, posibilidad de búsquedas, de marcado, de anotaciones personales, de complementos multimedia y un largo etcétera, tan largo como la imaginación de los creadores de hardware/ software y las exigencias del mercado lo extiendan). Es de señalar, e incluso habría que destacar, que el dispositivo lector no es un libro, sino un soporte que puede acoger un libro, del mismo modo que una bobina de papel para impresión en rotativa no será libro hasta que esté impresa con un determinado contenido y encuadernada.

\section{“En 2008 un 24,7\% de las editoriales españolas publicaron en soportes distintos del papel"}

Lo anteriormente mencionado se sustenta en lo que las definiciones de libro más autorizadas expresan. Así, el Diccionario de la Real Academia de la Lengua desde su vigésimo segunda edición (2001) señala como "libro" en su segunda acepción, la "Obra científica, literaria o de cualquier otra índole con extensión suficiente para formar volumen que pueda aparecer impreso o en otro soporte. Voy a escribir un libro. La editorial presentará el atlas en forma de libro electrónico”.

Por su parte, el Art. 2 de la Ley 10/2007, de 22 de junio, del libro, la lectura y las bibliotecas, dice: "A los efectos de esta ley se entiende por libro:

a) Libro: obra científica, artística, literaria o de cualquier otra índole que constituye una publicación unitaria en uno o varios volúmenes y que puede aparecer impresa o en cualquier otro soporte susceptible de lectura.

Se entienden incluidos en la definición de libro a los efectos de esta ley, los libros electrónicos y los libros que se publiquen o se difundan por internet o en otro soporte que pueda aparecer en el futuro, los materiales complementarios de carácter impreso, visual o audiovisual o sonoro que sean editados conjuntamente con el libro y que participen del carácter unitario del mismo, así como cualquier otra manifestación editorial".

Como puede apreciarse, existe y se recoge en el ordenamiento jurídico, un concepto de libro electrónico. Se constata su existencia (si bien su definición peca de equívoca, como si estuviera "en construcción") y que nuestra Ley del libro, la lectura y las bibliotecas, convierte a la lectura en el elemento clave para delimitar legalmente el concepto de "libro".

Queda claro que los dispositivos reproductores, por mucha importancia industrial que pudiera tener su penetración en el mercado y su influencia en la consolidación del mercado digital, son hardware, equiparables si se quiere a los pequeños electrodomésticos como los reproductores MP3, los teléfonos móviles, los lectores de videocasetes, de DVD o de discos compactos.

Parece que existe un acuerdo general en que cualquiera que sea el concepto del libro electrónico que se elija, éste debe cumplir tres características tecnológicas:

- utilización de la "tinta electrónica"

- gran capacidad de almacenamiento

- conectividad, que permita la incorporación de obras digitalizadas a los dispositivos lectores mediante los diferentes medios de conexión.

No obstante, aún queda un trabajo por hacer en cuanto al libro electrónico y el perfeccionamiento de su concepto, como su identificación precisa, en cualquiera de las modalidades en que vaya a ser explotado.

Ya se encuentran operando satisfactoriamente el ISBN -International standard book number-y el DOI -Digital object identifier-, sistemas que permiten la identificación, el primero de libros, y el segundo de objetos digitales (libros, artículos, imágenes...), que pueden ser integrados para la identificación de los e-books, lo que es recomendado por la Asociación de Editores de Estados Unidos de e-books. Mediante una clara identificación se hace posible que los derechos de propiedad intelectual a que esté sometido un determinado $e$-book dispongan de la trazabilidad necesaria para ser debidamente atendidos.

Otro de los aspectos que puede dificultar la evolución del libro electrónico es su fiscalidad.

En España hay tres tipos de IVA: el 4\%, el $7 \%$ y el $16 \%$. Los libros en soporte papel siempre se han incluido en el tipo reducido, hoy del 4\%, según el Art. 91 de la Ley 37/1992, reguladora del impuesto. En concreto así lo dispone el apartado 2 de dicho artículo que reza: 
“2) Los libros, periódicos y revistas que no contengan única o fundamentalmente publicidad, así como los elementos complementarios que se entreguen conjuntamente con estos bienes mediante precio único. Se comprenderán en este número las ejecuciones de obras que tengan como resultado inmediato la obtención de un libro, periódicos o revistas en pliego o en continuo, de un fotolito de dichos bienes o que consistan en la encuadernación de los mismos.

\section{"El libro electrónico goza desde diciembre de 2009 de un tipo de IVA idéntico al de los otros libros, el 4\%"}

A estos efectos tendrán la consideración de elemento complementario, las cintas magnetofónicas, discos, videocasetes y otros soportes sonoros o videograbadoras o similares que constituyan una unidad funcional con el libro, periódicos o revistas perfeccionando o complementando su contenido y que se venden con ellos, con las siguientes excepciones:

- los discos y cintas magnetofónicas que contengan exclusivamente obras musicales y cuyo valor de mercado sea superior al del libro, periódico o revista con el que se entregan conjuntamente.

- los videocasetes y otros soportes sonoros o medios magnéticos que contengan películas cinematográficas, programas o series de televisión de ficción o musicales y cuyo valor de mercado sea superior al del libro, periódico o revista con en el que se entrega conjuntamente".

Esta redacción recogía lo dispuesto en el Anexo III de la Sexta Directiva Comunitaria sobre el IVA, que ha sido recientemente modificada por la Directiva 2009/47 de la CE del Consejo de 5 de mayo de 2009.

A pesar de la definición del libro del Diccionario de la Real Academia de la Lengua y de la Ley del libro, la lectura y las bibliotecas, antes citados, los contenidos digitales -la esencia del libro electrónico- eran considerados prestación de servicios y no libros, y hasta ahora tributaban al $16 \%$.

Es evidente que esta situación impositiva suponía una amenaza para el avance del libro electrónico. Hasta el presente, los intentos para que los contenidos digitales editoriales fueran considerados fiscalmente como libros, no habían tenido éxito. No obstante, la Directiva 2009/47 de la CE abrió un nuevo escenario, ya que en ella se expresa la voluntad del legislador comunitario de abrir la puerta a los Estados miembros para que puedan aplicar tipos reducidos a las entregas de libros electrónicos, aclarándose en el nuevo texto que la referencia al libro es independiente del soporte en el que éste se produzca. Esto ha obligado a las autoridades fiscales a replantearse el concepto de libro y acercarse a lo ya aceptado por el Diccionario de la Real Academia y por la Ley del libro, la lectura y las bibliotecas, y así el libro electrónico gozará desde diciembre de 2009 de un tipo de IVA idéntico al de los otros libros, el $4 \%$.

Por otra parte, aún no está claro el modelo de negocio de los libros electrónicos pues éste no sólo consiste en descargar una determinada obra en un dispositivo lector en el que se almacene, sino que puede consistir también en descargas parciales, suscripciones a publicaciones referidas a determinados temas, consultas durante cierto tiempo, con o sin posibilidad de almacenar o imprimir, etc., y todo aquello que el mercado vaya demandando, pues las posibilidades del contenido digital son casi ilimitadas.

\section{"Las editoriales están trabajando en la creación de plataformas digitales de distribución y comercialización"}

El sector editorial español ha permanecido muy atento a la evolución de los modelos de edición y comercialización electrónica, como lo muestran los seminarios organizados en los últimos años en la Universidad Internacional Menéndez Pelayo (UIMP), por donde han pasado como ponentes los principales agentes de la edición digital estadounidense y europea.

Muestra de ello es el impulso a Dilve (Distribuidor de Información de Libros en Venta en España), realidad en la que ya han participado más de 500 editoriales con 230.000 títulos vivos, de los cuales 100.000 poseen información rica en contenidos; o una proyección de Dilve, el proyectoEncl@ve Editores-BNE, apoyado por el Plan Avanza del Ministerio de Industria, Turismo y Comercio, fruto de la colaboración entre la Biblioteca Nacional y la Federación de Gremios de Editores de España en el que participan ya 90 editoriales y que a finales de 2009 incorpora 1.350 libros digitales sometidos a derechos, por tanto de reciente publicación en la Red. A finales del año 2010 se prevé que 5.000 títulos formarán parte del catálogo de la Biblioteca Digital Hispánica, desde donde el usuario tendrá la posibilidad de tener acceso a un entorno gestionado por el editor (o entidad delegada) donde realizar las transacciones comerciales que convengan.

http://www.dilve.es

http://www.dilve.es/enclave 


\section{doc6 en 30 segundos}

\section{Nuestra misión}

Contribuir a aumentar la eficiencia de empresas y organizaciones a través de una eficaz gestión de la información y el conocimiento.

\section{La empresa}

Creada en el año 1988, especializada en gestión de la información, la documentación y el conocimiento.

Certificada con la ISO 9001:2000 por Bureau Veritas desde

Septiembre del 2000 en las siguientes actividades:

a CONSULTORES EN RECURSOS DE INFORMACIÓN

a GESTIÓN DEL CONOCIMIENTO

a INTRANET/EXTRANET/INTERNET

a EDICIÓN ELECTRÓNICA

a EXTERNALIZACIÓN DE SERVICIOS DOCUMENTALES

a PROVEEDORES DE RECURSOS ELECTRÓNICOS DE INFORMACIÓN

a SOLUCIONES EN GESTIÓN DOCUMENTAL

a CURSOS DE FORMACIÓN

\section{Nuestros valores}

Innovación permanente.

Satisfacción del cliente. Calidad

Profesionalidad / Cooperación con el cliente

Confidencialidad

Responsabilidad social y valores éticos

\section{Los clientes}

El principal activo de la empresa, junto con sus empleados.

Más de 900 clientes: empresas, laboratorios, administraciones públicas, universidades, hospitales, bufetes de abogados, museos, fundaciones, colegios profesionales.

\section{Nuestros profesionales}

Un equipo de más de 120 profesionales.

Una eficaz suma de conocimientos: informáticos y documentalistas con experiencia.

El $75 \%$ son licenciados superiores o diplomados en informática o documentación. 